\title{
Bilateral Ureteral Tapering and Secondary Ureteroneocystostomy for Late Stenosis in a Patient with Bladder Extrophy
}

\author{
Emanuela Altobelli Alfredo M. Bove Federico Sergi Maurizio Buscarini \\ Campus Biomedico, Urology Roma, Rome, Italy
}

\section{Key Words}

Bladder exstrophy $\cdot$ Hydronephrosis $\cdot$ Surgical technique
(UTIs) 20 years after bladder exstrophy (BE) repair, managed successfully by bilateral ureteral tapering and secondary ureteroneocystostomy.

\section{Case Report}

A 21-year-old woman with a history of BE was referred to our department for hematuria-dysuria syndrome and recurrent febrile UTIs.

Her surgical history started on the fourth day of life. During the first procedure she underwent bladder closure without osteotomy in a staged reconstructive approach. At 6 years for low bladder capacity, a gastrocystoplasty was performed. At the age of 10, she underwent a bilateral UR secondary Cohen for hydronephrosis secondary to vesicoureteral reflux (VUR). The last procedure was performed at 19 years with the removal of umbilical endometriosis.

On physical examination she presented with lower midline and Pfannenstiel scars of previous procedures, pubis diastasis, bifid clitoris, stenotic and anteriorly displaced vagina and short perineum with the anus directly behind the urogenital diaphragm. No alterations on blood tests, with normal renal function (creatinine $0.7 \mathrm{mg} / \mathrm{dl}$ ). Urine culture showed $>100,000 \mathrm{CFU}$ of $E$. Coli and a specific antibiotic therapy was prescribed for 7 days. To treat the hematuria-dysuria syndrome a proton pump inhibitor therapy was started with success.

A severe bilateral hydronephrosis, greater on the left, associated to a compression of renal parenchyma, was highlighted at the ultrasounds and confirmed at the CT scan, with a diameter of 23 and $40 \mathrm{~mm}$ on right and left ureter, respectively (fig. 1). Right pelvis measured $33 \mathrm{~mm}$ and left pelvis $43 \mathrm{~mm}$. A high post-void residual volume was evident.

\section{KARGER}

Fax +4161306 1234

E-Mail karger@karger.ch

www.karger.com
(C) 2012 S. Karger AG, Basel

1015-9770/12/0064-0212\$38.00/0

Accessible online at:

www.karger.com/cur
Emanuela Altobelli, MD

Campus Biomedico, Urology Roma

Via Alvaro del Portillo 200

IT-00128 Rome (Italy)

E-Mail e.altobelli@unicampus.it 


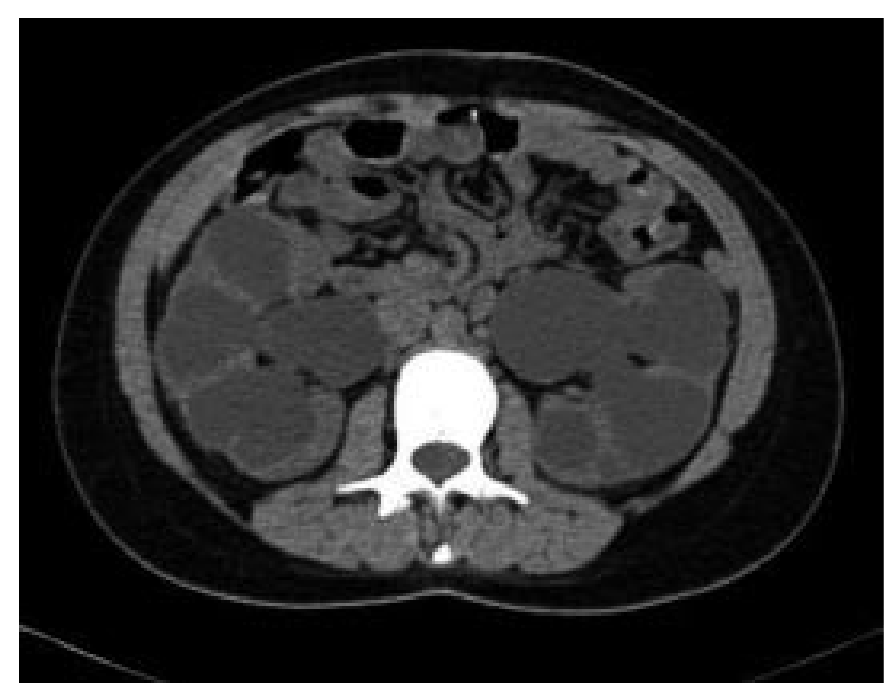

Fig. 1. Preoperative CT scan.

Patient refused self clean intermittent catheterisation and urodynamic evaluation because of childhood catheter trauma. So to investigate the symptoms we decided to perform under general anesthesia a cystourethroscopy that showed a long and twisting urethra with a bladder fool of mucus without alterations of urothelial and gastric mucosa. Cross trigonal ureteral meatus were stenotic bilaterally and retrograde stenting was not possible. During the same procedure, a retrograde cystourethrogram was executed without evidence of VUR. One month later she elected to undergo open surgery.

\section{Surgical Technique}

Because of previous surgical procedures, a laparoscopic approach was not indicated. An 18Ch transurethral Foley catheter was inserted. Patient was placed in supine position with $15^{\circ}$ Trendelenburg tilt. After steril draping a lower midline incision was performed. After peritoneal incision the exposure was obtained with a self-retaining retractor. The bulging and dilated ureters were identified extravesically and gently placed on traction with a vessel loop. Ureters were mobilized to the ureterovesical junction and a stiff and severe anastomotic stricture determining obstruction was verified bilaterally. Ureters were divided and hiatus oversewn. A 4-0 polyglactin stay suture was placed on the distal end of each ureter. Both ureters were fully mobilized to the extent of the exposure at the peritoneal reflection. Once the ureter was

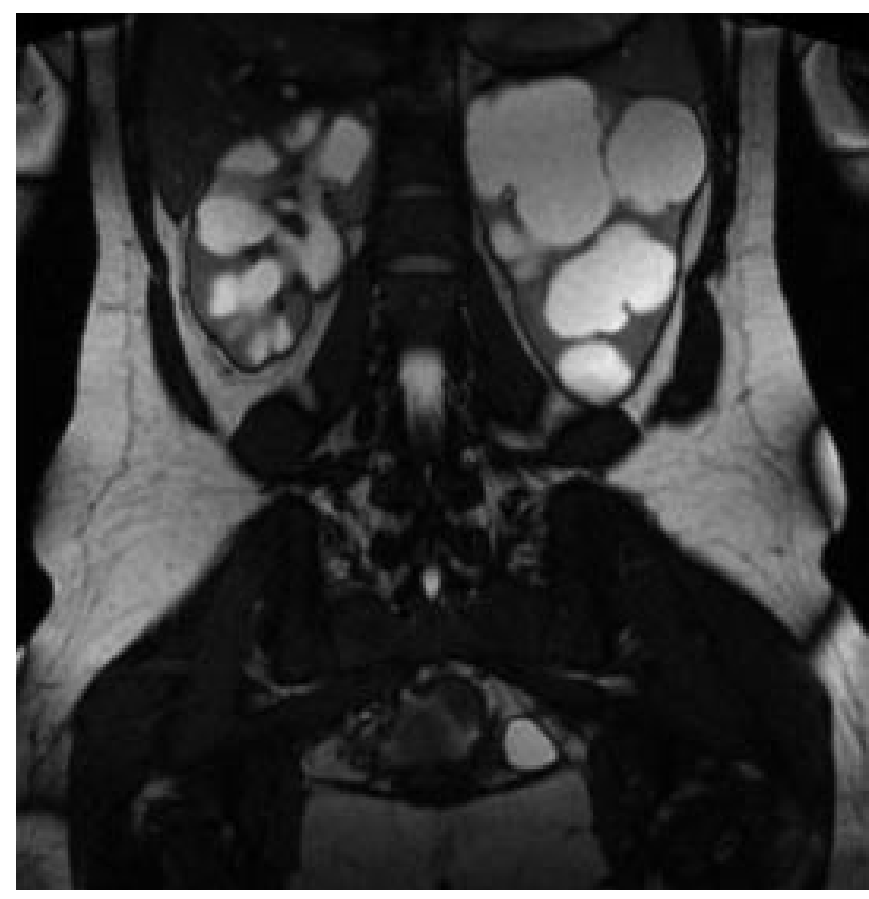

Fig. 2. Postoperative MRI.

mobilized and decompressed, decision was made to proceed with extensive ureteral tailoring. To achieve a tunnel length to diameter ratio of at least 5:1, a $10 \mathrm{Ch}$ catheter was placed in the lumen of each ureter and these were tapered using Hendren clamps. Obviously only the intramural part of the ureter was tapered. The bladder was opened via a midline cystostomy and the ureter was reimplanted with an anti-reflux intravesical anastomosis according to Glenn-Anderson technique on left ureter. Right ureter was reimplanted with Lich-Gregoire extravesical approach. A mono-J ureteral catheter was retrograde positioned in both ureters. Oversewning detrusorrhaphy was performed for bladder closure. A perivesical Jackson-Pratt drain was left indwelling.

\section{Results}

Postoperatively, orals were allowed on day 1 . Drain and Foley catheter were removed on day 3 and 6, respectively. Cystoscopy and cystourethrogram were performed as an outpatient 4 weeks postoperatively to remove ureteral stents and transurethral catheter. Urine culture 1 month after surgery was positive for $E$. Coli growth and antibiotic therapy was prescribed based on the antibiogram. 
A postoperative abdominal ultrasound performed 3 months after surgery showed left hydronephrosis, confirmed at the MRI, showing left hydroureteronephrosis (33 $\mathrm{mm}$ of diameter) with anastomotic stenosis and a regular right ureter (fig. 2). Three-month urine culture was negative for bacterial growth. Patient was asymptomatic and her quality of life was improved.

\section{Discussion}

After initial closure, all exstrophy patients have VUR. In $\mathrm{BE}$, the ureters dip deeply into the pelvis before entering the bladder in a nearly cephalad direction, emerging through the bladder muscle with a minimal submucosal tunnel [1]. This reflux is usually managed with antimicrobial prophylaxis, surveillance, and ureteral reimplantation concurrent with bladder neck plasty [2-5]. Our patient developed recurrent UTIs and worsening hydronephrosis, and at the age of 10 underwent first bilateral UR according to Cohen's technique. During the procedure bladder neck plasty was not performed.

However UR is effective in reducing postoperative pyelonephritis [6], and UTI is the most common complication. There is surprisingly little literature describing the long-term clinical outcomes after UR. The International Reflux Study in Children prospectively compared the effects of successful surgery and effective medical management on the incidence of UTIs. During a followup of 5 years that study reported an incidence of $38 \%$ of infections of the lower urinary tract among conservatively treated patients, compared with $39 \%$ among those treated by surgery. The incidence of pyelonephritis was 21 and $10 \%$, respectively, and was statistically significantly different [7]. In another long-term, retrospective study of patients 10 years after UR, Beetz et al. [8] found that, among the $83.5 \%$ of patients they could contact, $17 \%$ had experienced postoperative febrile UTI. In contrast to these high rates of postoperative pyelonephritis, Whittam et al. [9] reported in a recent series that of 395 patients who underwent UR febrile UTI was diagnosed in just $4.6 \%$, although the follow-up time was relatively short at a mean of 15 months. Accordingly, Cooper et al. [10] reported an incidence of $37.6 \%$ of UTIs among 96 women who had UR in childhood and who were followed for 16-25 years afterward. As emphasized by Mor et al. [11] there is the need to establish a protocol for the long-term follow-up of patients who have had UR during childhood. Even patients who were managed successfully by surgery are prone to recurrent UTIs, progressive renal scarring, hypertension and complications during pregnancy. Our patient present only recurrent febrile UTIs associated to severe hydronephrosis. The primary complication that is assessed by postoperative imaging is obstruction, and presents clinically in addition to ultrasonographically [12-14]. Ellsworth et al. [15] reported on 3 cases of ureteral obstruction during the first week after surgery. All of these patients were symptomatic and were treated with the placement of a double-J stent. Androulakakis et al. [16] also reported 3 incidences of obstruction, all of which presented symptomatically, and only one of which required reoperation. Additionally, temporary obstructive situations may occur following surgery, including ureteral edema, intramural hematomas applying pressure on the ureter, temporary lack of peristalsis in the operated ureter, and kinking of the ureter at the hiatus as the bladder fills [17]. These obstructions can be partial and self limiting following surgery, are varied between each patient, and contribute to the length of time it takes for postoperative hydronephrosis to resolve. They do not represent clinically important obstruction, however [1820]. All this study evaluates only a short-term follow-up. There are no studies about worsening hydronephrosis 20 years after UR.

\section{Conclusions}

Even if there are some studies about the postoperative UTIs and hydronephrosis, there are no data about reintervention 20 years after primary UR. Our case demonstrates the success of UR associated to ureteral tapering even after a prior reimplantation in BE patient. 


\section{References}

1 Canning DA, Gearhart JP, Peppas DS, Jeffs RD: The cephalotrigonal reimplant in bladder neck reconstruction for patients with exstrophy or epispadias. J Urol 1993;150:156-158.

$\checkmark 2$ Grady RW, Mitchell ME: Complete primary repair of exstrophy. J Urol 1999;162:14151420.

-3 Nisonson I, Lattimer JK: How well can the exstrophied bladder work? J Urol 1972;107: 664-666.

4 Baker LA, Gearhart JP: The staged approach to bladder exstrophy closure and the role of osteotomies. World J Urol 1998;16:205211.

5 Mathews R, Hubbard JS, Gearhart JP: Ureteral reimplantation before bladder neck plasty in the reconstruction of bladder exstrophy: indications and outcomes. Urology 2003;61: 820-824.

6 Nelson CP, Hubert KC, Kokorowski PJ, Huang L, Prasad MM, Rosoklija I, Retik AB: Long-term incidence of urinary tract infection after ureteral reimplantation for primary vesicoureteral reflux. J Pediatr Urol 2012; Epub ahead of print.

7 Jodal U, Koskimies O, Hanson E, Löhr G, Olbing H, Smellie J, Tamminen-Möbius T: Infection pattern in children with vesicoureteral reflux randomly allocated to operation or long-term antibacterial prophylaxis. The International Reflux Study in Children. J Urol 1992;148:1650-1652. $\checkmark 8$ Beetz R, Mannhardt W, Fisch M, Stein R, Thuroff JW: Long-term followup of 158 young adults surgically treated for vesicoureteral reflux in childhood: the ongoing risk of urinary tract infections. J Urol 2002;168:704 707.

9 Whittam BM, Thomasch JR, Makari JH, Tanaka ST, Thomas JC, Pope JC 4th, Adams MC, Brock JW 3rd: Febrile urinary tract infection after ureteroneocystostomy: a contemporary assessment at a single institution. J Urol 2010;183:688-692.

10 Cooper A, Atwell J: A long-term follow-up of surgically treated vesicoureteric reflux in girls. J Pediatr Surg 1993;28:1034-1036.

11 Mor Y, Leibovitch I, Zalts R, Lotan D, Jonas P, Ramon J: Analysis of the long term outcome of surgically corrected vesico-ureteric reflux. BJU Int 2003;92:97-100.

12 El Imam Mohammed M, Omram M, Nugud F, El Hassan M, Taha O: Evaluation of ureteral reimplantation in 65 Sudanese patients. Saudi J Kidney Dis Transpl 2005;16:166-170.

13 Jodal U, Smellie JM, Lax H, Hoyer PF: Tenyear results of randomized treatment of children with severe vesicoureteral reflux. Final report of the International Reflux Study in Children. Pediatr Nephrol 2006;21:785-792.

14 Kennelly MJ, Bloom DA, Ritchey ML, Panzl AC: Outcome analysis of bilateral Cohen cross-trigonal ureteroneocystostomy. Urology 1995;46:393-395.
15 Ellsworth PI, Freilich DA, Lahey S: Cohen cross-trigonal ureteral reimplantation: is a one-year post-operative renal ultrasound scan necessary after normal initial postoperative ultrasound findings? Urology 2008;71:10551058.

16 Androulakakis PA, Stefanidis AA, Karamanolakis DK, Moutzouris V, Koussidis G: The long-term outcome of bilateral Cohen ureteric reimplantation under a common submucosal tunnel. BJU Int 2003;91:853-855.

17 Khoury AE, Bagli DJ: Vesicoureteral reflux; in Wein AJ, Kavoussi LS, Novick AC, Partin AW, Peters CA (eds): Campbell-Walsh urology. ed 10. Elsevier Saunders, 2011, pp3267-3309.

18 Falkensammer ML, Gobet R, Stauffer UG, Weber DM: To Cohen and forget? Evaluation of postoperative imaging studies after transtrigonal ureteric reimplantation for vesicoureteric reflux in children. Urol Int 2008; $81: 218-221$.

$>19$ Charbonneau SG, Tackett LD, Gray EH, Caesar RE, Caldamone AA: Is long-term sonographic followup necessary after uncomplicated ureteral reimplantation in children? J Urol 2005; 174:1429-1431.

20 Bomalaski MD, Ritchey ML, Bloom DA: What imaging studies are necessary to determine outcome after ureteroneocystostomy? J Urol 1997;158:1226-1228. 